\title{
Coping Strategies and Quality of Life in Elderly Population
}

\author{
Marco Marcelo León-Navarrete ${ }^{1 *}$, María Elena Flores-Villavicencio², \\ Neyda Mendoza-Ruvalcaba ${ }^{2}$, Cecilia Colunga-Rodríguez ${ }^{2,3}$, Martha Leticia Salazar-Garza ${ }^{4}$, \\ Luis Edmundo Sarabia-López ${ }^{1}$, Guido Germán Albán-Pérez ${ }^{1}$
}

\author{
${ }^{1}$ Universidad Central del Ecuador, Quito, Ecuador \\ ${ }^{2}$ Universidad de Guadalajara, Guadalajara, México \\ ${ }^{3}$ Instituto Mexicano del Seguro Social, Guadalajara, México \\ ${ }^{4}$ Universidad Autónoma de Aguascalientes, Aguascalientes, México \\ Email: *psiquemarcelo_ankara@outlook.es
}

How to cite this paper: León-Navarrete, M.M., Flores-Villavicencio, M.E., Mendoza-Ruvalcaba, N., Colunga-Rodríguez, C., Salazar-Garza, M.L., Sarabia-López, L.E. and Albán-Pérez, G.G. (2017) Coping Strategies and Quality of Life in Elderly Population. Open Journal of Social Sciences, 5, 207-216.

https://doi.org/10.4236/jss.2017.510017

Received: September 7, 2017

Accepted: October 24, 2017

Published: October 27, 2017

Copyright (c) 2017 by authors and Scientific Research Publishing Inc. This work is licensed under the Creative Commons Attribution International License (CC BY 4.0).

http://creativecommons.org/licenses/by/4.0/

\begin{abstract}
The elderly represent a population group that requires a specific and integral approach that promotes its wellbeing and health. There are contextual factors experience during this life stage, such as the generation of diseases, which can influence negatively central aspects of life. One of the constructs that could be affected by these factors is the Quality of Life (QOL). The interaction between the contextual variables and QOL is mediated by the Coping Strategies (CS) that the individual applies to cope with the environmental challenges. The aim of this research was to analyze the differences in Quality of Life levels of the elderly, controlling for the type of Coping Strategies implemented. A transversal study was conducted, including a sample of 100 senior adults of the Metropolitan District of Quito, Ecuador. The participants signed a inform consent form and answered the Inventario de Estrategias de Afrontamiento (Survey of Coping Strategies) and the FUMAT Scale for the evaluation of QOL. The mean age was 74.6 years $(\mathrm{SD}=5.5)$, being $64 \%$ women. We observed percentages lower than $50 \%$ in all QOL dimensions, being the material wellbeing, the subscale with lower scores. The CS more frequently reported were the problem resolution, the desiderative thinking and the self-criticism. The participants that referred to use the emotional expression as a coping strategy presented higher levels of QOL. The Quality of Life in the elderly is influenced by contextual factors, being necessary to provide them with strategies that can be used to cope with the life challenges in a more effective and adaptive way.
\end{abstract}

\section{Keywords}

Elderly, Quality of Life, Coping Strategies 


\section{Introduction}

The mature and late adulthood represents a stage in which the individual continues to experience important physical, emotional and social changes. The elderly represents a population group that requires of a specific and multidimensional approach that promotes the wellbeing and health. In this stage, different types of factors, such as the appearance of diseases, the beginning of the cognitive impairment and the loss of autonomy, represent changes that can affect central aspects of human development, such as Quality of Life [1].

Quality of Life (QOL) is defined as a multidimensional concept constructed from the individual valuation of the personal, social and contextual situation [2]. This perception is developed from the values, standards and expectative of each person, being a sum of the objective and subjective experiences that impact the individual's feelings of wellbeing [3] [4]. The impact that the changes experienced by the elderly have in different areas of life, such as QOL, is relevant because it associates with the onset of important problems, such as depression and suicide [5].

A mediator variable between the contextual factors and its impact in QOL are the Coping Strategies (CS). Lazarus and Folkman (1984, p. 141), define the CS as cognitive and behavioral efforts perform by an individual, in order to face a specific demand from the environment, which exceeds its resources [6]. There are two main types of CS: One centered in the problem, aiming to change the problematic situation; and other, centered in the emotion, in which the person seeks to control the emotional response triggered by the problem [7]. The coping style, when it includes adaptive responses, can represent a protective factor that mitigates the stress effects, preventing the onset of other alterations [8]. The Coping Strategies in the elderly is a topic that requires more attention, being important to identify the responses that better mediate the stress effects of contextual variables during this life stage.

Considering the previously mentioned, it is evident that QOL is influenced by the changes experience by the elderly. The Coping Strategies are cognitive and behavioral tools that can help the elder to better face these changes in life. However, despite the relevance that these elements have in the prevention of physical and mental health problems in the elder, there is a short amount of research about this topic. The aim of this study was to analyze the differences in Quality of Life levels of the elderly, controlling for the type of Coping Strategies implemented.

\section{Research Settings}

Ecuador is a Latin-American country with a population of $14,483,499$, from which $6.49 \%$ are elderly [9]. The country is divided in metropolitan districts. This research was conducted in the Metropolitan District of Quito (MDQ), the capital of Ecuador, whit a population of $1,523,274$, from which $7.7 \%$ are elderly [9] [10]. 
As in many countries, Ecuador has a growing elderly population, starting to gather attention from governments and institutions, in Quito, six of each 100 persons are elderly (Morales, 2008, p. 12). The culture about this life stage tends to involve respect and attention, however, there is an important part of the population that do not receive the health, emotional and social supports required.

\section{Methodology}

\subsection{Participants}

We included a sample of 100 elder adults of the Metropolitan District of Quito, Ecuador. The participants were selected according to age, including adults older than 65 years, being recruited using an opportunity sampling [10]. We attended community and religious centers located in the previously mentioned zone, in order to invite the adults to participate in the research.

\subsection{Measurement Instruments}

\subsubsection{Coping Strategies}

We used the Inventario de Estrategias de Afrontamiento (Coping Strategies Inventory) in its adapted version for Spanish by Cano, Rodríguez and García (2006) [11]. Validated for its use in the elderly with a Cronbach's Alpha from 0.66 to 0.88 for the subscales of the instrument [12]. The survey is applied in a self-report format, starting with the instruction to describe a stressing situation experienced in the last five years. After this, 40 items are presented, exploring the frequency of use of different types of Coping Strategies. The items are divided into eight dimensions, which regard to different typed of CS: problem resolution, referring to the application of strategies focus to change the stressful situation; cognitive restructuration, regarding to the modification of the meaning of the stressful situation; social support, in which the attention is center in seeking support from others; emotional expression, were the focus is to externalize the emotions generated from the stress process; problem avoidance, regarding to the intention of avoid or denied thoughts and behaviors related to the stressful situation; desiderative thinking, referring to the desire to change reality in order to make it less stressful; social withdraw, in which the person avoids the individuals associated to its emotional response against the problem; self-criticism, includes sel-blaime for the generation of the event and/or for the response against it. The answer options are presented in a four point Likert scale, going from "not at all" to "very often". The instrument includes evaluation scales for each dimension, categorizing the total score for each coping strategy according to the level of use into: not at all, sometimes, often and very often.

\subsubsection{Quality of Life}

For the evaluation of QOL we used the FUMAT scale, validated with a Cronbach's Alpha of 0.96 [13]. The instrument is designed for its application with the elderly and disability populations. It includes 80 items divided in seven dimen- 
sions: emotional wellbeing (satisfaction, self-concept, stress absence); interpersonal relationships (interactions, relationships and supports); material wellbeing (economic status, employment and living place situation); personal development (education, emotional competence and performance); physical wellbeing (health, everyday activities, health care services and free time); self-determination (autonomy, goals/values, choices); social inclusion (integration and participation in the community, community roles and social supports), and rights (legal/human rights). The answer options are in a four point Likert scale, going from "never" to "almost always". The interpretation of the results allows to generate a global Quality of Life index and percentages for each dimension.

\subsection{Data Collection Procedure}

Initially, we schedule a session with authorities of different institutions that work with the elderly in the Metropolitan District of Quito, Ecuador (community and religious). In these meetings, we explained the aims, procedures and ethical considerations for the development of the research. Once the institutions agreed to participated, an inform consent form was signed by the administrative personal. In a second moment, we conducted informative sessions with the elderly, explaining the research's aims and procedures. We applied the Mini-Mental State Examination (MMSE) to the participants interested in the research, aiming to identify individuals that presented an important level of cognitive impairment, excluding them of the sample due to ethical considerations [14]. The participants that agreed to participate received information about the ethical aspects of the study, proceeding to signed an inform consent letter. We applied the measurement instruments in the same session.

\subsection{Data Analysis}

A database in Excel 2010 was elaborated, analyzing with SPSS 20. We applied descriptive statistics to the sociodemographic data. For the data collected from the measurement instruments, we used central tendency and dispersion statistics. The differences in the Quality of Life levels were calculated using Student's $\mathrm{T}$ test, controlling for coping strategies

\section{Results}

\subsection{Sociodemographic Characteristics}

The results obtained about the sociodemographic data is presented in Table 1. We found that the mean age was 74.6 years $(S D=5.5)$, with a higher prevalence of women, and a majority of married participants with a middle school predominant educational level.

\subsection{Coping Strategies}

Regarding the results from the Inventario de Estrategias de Afrontamiento (Coping Strategies Inventory), we observed that the most frequently used 
Table 1. Sociodemographic characteristics of the participants.

\begin{tabular}{|c|c|c|}
\hline & & Percentage \\
\hline \multirow{5}{*}{ Gender } & Male & 36 \\
\hline & & \\
\hline & Female & 64 \\
\hline & 65 to 70 & 53 \\
\hline & 71 to 75 & 12 \\
\hline \multirow[t]{3}{*}{ Age } & 76 to 80 & 9 \\
\hline & 81 to 90 & 21 \\
\hline & 90 and more & 5 \\
\hline \multirow[t]{4}{*}{ School level } & Elementary & 37 \\
\hline & Middle school & 58 \\
\hline & Thecnical & 2 \\
\hline & Third level & 3 \\
\hline \multirow[t]{6}{*}{ Civil status } & Single & 6 \\
\hline & Married & 58 \\
\hline & Divorced & 9 \\
\hline & Separated & 5 \\
\hline & Free union & 11 \\
\hline & Widowhood & 11 \\
\hline
\end{tabular}

$\mathrm{N}=245$.

strategies were the problem resolution, the desiderative thinking and the self-criticism. Meanwhile, the less reported were seeking for social support, cognitive restructuration and social withdraw (Table 2).

Regarding the total score of the inventory, we found that $77 \%$ of the participants referred to use coping strategies very often, while only $23 \%$ mentioned to use them only often.

\subsection{Quality of Life}

The FUMAT's survey provided with percentiles and a Quality of Life index for each dimension, finding that "material wellbeing" was the area with the lower scores. Likewise, the dimensions "Interpersonal relationships" and "Physical wellbeing" maintained percentiles lower than $30 \%$. The rest of the dimensions scored within percentiles lower than $50 \%$, being the self-determination one of the higher scores (Table 3 ).

\subsection{Differences in Quality of Life Controlling for Coping Strategies}

Finally, we analyzed the differences in levels of QOL in elderly controlling for the coping strategies implemented, using One-way analysis of variance ANOVA. 
Table 2. Coping strategies applied by elderly in the Metropolitan District of Quito.

\begin{tabular}{ccccc}
\hline & \multicolumn{4}{c}{ Cathegorization of the frequency } \\
\cline { 2 - 5 } Coping strategies & Not at all & Sometimes & Often & Very often \\
\cline { 2 - 5 } & $\mathrm{n}$ & $\mathrm{n}$ & $\mathrm{n}$ & $\mathrm{n}$ \\
\hline Problem resolution & - & - & 82 & 18 \\
Self-criticism & - & 7 & 93 & - \\
Emotional expression & - & 27 & 72 & 1 \\
Desiderative thinking & - & - & 98 & 2 \\
Social support & 6 & 79 & 13 & 2 \\
Cognitive restructuration & - & 79 & 20 & 1 \\
Problem avoidance & - & 29 & 64 & 7 \\
Social withdraw & - & 67 & 32 & 1 \\
\hline
\end{tabular}

$\mathrm{N}=245 ; \mathrm{n}=$ frequency.

Table 3. Quality of Life profile for elderly in the Metropolitan District of Quito.

\begin{tabular}{|c|c|c|c|c|c|c|c|c|c|}
\hline Percentil & EW & IR & MW & $\mathrm{PD}$ & PW & SD & SI & $\mathrm{R}$ & QOL Index \\
\hline 99 & & & & & & & & & \\
\hline 95 & & & & & & & & & $>122$ \\
\hline 90 & & & & & & & & & $118-122$ \\
\hline 85 & & & & & & & & & $115-117$ \\
\hline 80 & & & & & & & & & $112-114$ \\
\hline 75 & & & & & & & & & $110-111$ \\
\hline 70 & & & & & & & & & $107-109$ \\
\hline 65 & & & & & & & & & $105-106$ \\
\hline 60 & & & & & & & & & $103-104$ \\
\hline 55 & & & & & & & & & 102 \\
\hline 50 & & & & & & & & & $99-101$ \\
\hline 45 & & & & & & & & & 98 \\
\hline 40 & & & & & & & & & $95-97$ \\
\hline 35 & & & & & & & & & 94 \\
\hline 30 & & & & & & & & & $92-93$ \\
\hline 25 & & & & & & & & & $90-91$ \\
\hline 20 & & & & & & & & & $87-89$ \\
\hline 15 & & & & & & & & & $83-86$ \\
\hline 10 & & & & & & & & & $78-82$ \\
\hline 5 & & & & & & & & & $71-77$ \\
\hline 1 & & & & & & & & & $<71$ \\
\hline
\end{tabular}

Note: EW, emotional wellbeing; IR, interpersonal relationships; MW, material wellbeing; PD, personal development; $\mathrm{PW}$, physical wellbeing; SD, self-determination; SI, social inclusion; $\mathrm{R}$, rights. 
We observed that, only the participants that referred to implement the "emotional expression" strategy present differences in the quality of life levels (Table 4).

\section{Discussion}

The aim of this research was to analyze the differences in Quality of Life levels of the elderly, controlling for the type of Coping Strategies implemented. Beginning to talk about the Coping Strategies, we observed that the most commonly used are the problem resolution, the desiderative thinking and the self-criticism. The first corresponds to an adaptive approach center in the problem, however, the other two represent coping mechanisms qualify as maladaptive, centered in the problem and the emotion [15]. Authors such as Gonzalez and Padilla (2006), have pointed out that the elderly tend to cope with stressing situations, mainly with answers focus in the problem, promoting a reality centralize approach. However, it is interesting that in the second and third place we found coping mechanism centered in the desire to change reality and to self-criticize. This diversity of Coping Strategies reflects the variety of answers that a person can generate against a stressful event, highlighting the importance to provide the skills necessary to promote more adaptive coping mechanisms. The individuals that develop adaptive CS tend to be more resilience when facing everyday problems [8]. As mentioned by Mayordomo, Sales, Satorres and Blasco (2015), the adult in this life stage, faces important changes and losses, which require an important adaptation response from the person. Thus, it is necessary to develop interventions that promote the integration of more adaptive Coping Strategies with this population group [7].

Regarding the Quality of Life, we found that all dimensions presented percentages lower than $50 \%$, being "material wellbeing" one of the subscales with

Table 4. Differences in Quality of Life scores controlling for coping strategies.

\begin{tabular}{|c|c|c|c|c|c|c|c|c|c|}
\hline Coping strategies & EW & IR & MW & $\mathrm{PD}$ & PW & $\mathrm{SD}$ & SI & $\mathrm{R}$ & $\begin{array}{c}\text { Total QOL } \\
\text { score }\end{array}$ \\
\hline Problem resolution & 0.181 & 0.388 & 0.328 & 0.722 & 0.695 & 0.112 & 0.255 & 0.450 & 0.619 \\
\hline Self-criticism & 0.294 & 0.946 & 0.081 & 0.908 & 0.643 & 0.117 & 0.966 & 0.885 & 0.430 \\
\hline $\begin{array}{l}\text { Emotional } \\
\text { expression }\end{array}$ & 0.040 & 0.310 & 0.100 & 0.281 & 0.656 & 0.002 & 0.592 & 0.451 & 0.056 \\
\hline $\begin{array}{l}\text { Desiderative } \\
\text { thinking }\end{array}$ & 0.311 & 0.980 & 0.351 & 0.914 & 0.149 & 0.340 & 0.696 & 0.892 & 0.378 \\
\hline Social support & 0.962 & 0.385 & 0.197 & 0.601 & 0.284 & 0.582 & 0.144 & 0.763 & 0.245 \\
\hline $\begin{array}{l}\text { Cognitive } \\
\text { restructuration }\end{array}$ & 0.918 & 0.313 & 0.584 & 0.455 & 0.267 & 0.451 & 0.545 & 0.409 & 0.450 \\
\hline Problem avoidance & 0.211 & 0.649 & 0.549 & 0.976 & 0.766 & 0.182 & 0.711 & 0.844 & 0.764 \\
\hline Social withdraw & 0.983 & 0.459 & 0.549 & 0.505 & 0.307 & 0.823 & 0.072 & 0.980 & 0.441 \\
\hline
\end{tabular}

Note: EW, emotional wellbeing; IR, interpersonal relationships; MW, material wellbeing; PD, personal development; PW, physical wellbeing; SD, self-determination; SI, social integration; R, rights. Bolden values represent $\mathrm{P}<0.05$. 
significantly low scores. This can be explained because the elderly experience important economic changes, such as the separation from work life and the beginning of the necessity to receive medical and social supports that are not always included in the government offer services [16]. Situation that originates the beginning of the economical dependency from others, a complex process that could be influencing in this result. In a second and third place, the dimensions "interpersonal relationships" and "physical wellbeing" presented with low scores. Different authors point out that during this life stage, it is common that diseases initiate or worsen, affecting the elderly's autonomy and social interactions [4] [17]. It is necessary to approach this result in future researches, including elderly population with different health status, making possible to develop comparisons in the QOL levels, and to identify the possible factors affecting this construct.

We also evaluated the differences in the Quality of Life controlling for the Coping Strategies implemented. The findings indicate that the elderly that referred to use "emotional expression" as a Coping Strategy, presented better scores of QOL in the dimensions "emotional wellbeing", "self-determination" and for the general index. This strategy is categorized as an adaptive answer center in the emotion, relating to the need to release the emotions generated by the stressful situation [15]. Despite the more frequently used Coping Strategies are centered in the problem (problem resolution and desiderative thinking), the cope mechanism that seems to promote better levels of Quality of Life is center in emotion. This can be explained because, it is probable that elder adults that have more opportunities to express feelings and emotions, get access to more social support [18]. It is important to complete these analyses with other studies that include family and contextual variables, aiming to analyze the role played by the environment in the Coping Strategies that influence positively the QOL levels.

This research allowed to gather more information about the elderly's perception of Quality of Life and the Coping Strategies applied to cope with life problems. Likewise, it was possible to identify the CS that seems to favor better QOL levels, opening new topics to approach in future studies. However, despite its important contributions, the study has some limitations that need to be approach. One limitation is the sample size, it would be necessary to develop another research that includes a larger sample, promoting the inclusion of individuals from other districts or countries, allowing to generalize and compare the results. In addition, it is important to develop future research that includes other variables of human development, such as wellbeing and satisfaction, aiming to obtain a more complete evaluation of the reality of the elder adult and those factors that promote a greater sense of wellbeing. Finally, the results could be complete with the development of other studies that include different methodological designs and analysis.

\section{Conclusions}

The elder adult represent a particularly vulnerable population, considering they face important changes that represent a challenge and require an important set 
of adaptation skills. Factors such as diseases can impact key elements of development, being one of them the Quality of Life. In this research, we found that the elderly referred important alterations in areas such as material wellbeing, interpersonal relationships and physical wellbeing. We conclude it is important to explore this result in future research and develop interventions that promote the appropriation of skills that allow this population to reach a better stay of wellbeing and health.

The Coping Strategies function as a mediator of the impact that life events have in the Quality of Life. We observe that participants that refer to use coping mechanism such as "emotional expression" presented better Quality of Life scores. This allows to conclude that, it is probable that there is an association between having a safe space to express emotions and a better QOL, maybe because it could favor the accessibility to social support. However, it is a hypothesis that needs to be approach deeply in future studies, aiming to identify the variables that make a difference. It is necessary to develop more applied research that provides the necessary skills to cope with the everyday problems in a more effective and adaptive manner.

The conclusions developed from this research have important significance in different areas. From the practical approach, it would be important to include this population in the development of future interventions and public policies, in order to apply these research findings and the future results from other studies, into practical actions that promote a better wellbeing in the elderly. Socially, it would be important to develop more inclusion and health policies focus in the elderly, in order to promote better QOL, along with other important outcomes. From the academic approach, as mentioned before, it is necessary to keep developing researches that include this population, in order to develop more scientific evidence that promotes the generation of promotion and prevention strategies.

\section{References}

[1] González, A. and Padilla, A. (2006) Quality of Life and Coping Strategies against problems and Diseases in Mexican City Elderly Population. Universitas Psychologica, 5, 501-509.

[2] Quintero, G. and González, U. (1997) Quality of Life, Socioeconomically Context and Health in Elderly Population. In: Buendía, J., Ed., Gerontology and Health: Current Perspectives, Biblioteca Nueva, Madrid, 129-145.

[3] Aranibar, P. (2001) Conceptual Approach to the Elderly Situation in Latin America. Naciones Unidas, Santiago de Chile, 23.

[4] Estrada, A., Cardona, D., Segura, A., Chavarriaga, L., Ordóñez, J. and Osorio, J. (2011) Quality of Life in Institutionalized Elderly People of Medellin. Biomédica, 31, 492-502. https://doi.org/10.7705/biomedica.v31i4.399

[5] Marty, M., Segal, D. and Coolidge, F. (2010) Relationships among Dispositional Coping Strategies, Suicidal Ideation, and Protective Factors against Suicide in Older Adults. Aging \& Mental Health, 14, 1015-1023. https://doi.org/10.1080/13607863.2010.501068 
[6] Lazarus, R. and Folkman, S. (1984) Stress Appraisal and Coping. Springer, New York, 141.

[7] Mayordomo, T., Sales, A., Satorres, E. and Blasco, C. (2015) Coping Strategies in Older Adults as a Function of Sociodemographic Variables. Escritos de Psicología, 8, 26-32. https://doi.org/10.5231/psy.writ.2015.2904

[8] Tomás, J., Sancho, P., Melendez, J. and Mayordomo, T. (2012) Resilience and Coping as Predictors of General Well-Being in the Elderly: A Structural Equation Modeling Approach. Aging \& Mental Health, 16, 317-326. https://doi.org/10.1080/13607863.2011.615737

[9] Carrión, D., Flores, G., Jalkh, R., Santi, L., Núñez, S., Chanataxi, V., Morillo, G. and Villarreal, M.I. (2013) Equity Agenda of the Elderly. Ministry of Social and Economic Inclusion, Quito, 34.

[10] Morales, V. (2008) The Elderly in Quito, Sociodemographic and Socioeconomic Situation. 12.

http://www.ecuadorencifras.gob.ec/documentos/webinec/Bibliotecas/Estudios/Estu di-

os_Economicos/Evolucion_de_la_indus_Alimen_Beb_2001-2006/Poblac_Adulto_ Mayor.pdf

[11] Cano, G., Rodríguez, F. and García, M. (2007) Adaptación española del Inventario de Estrategias de Afrontamiento. Actas Españolas de Psiquiatría, 35, 29-39.

[12] Rubio, L., Dumitrache, C., Cordón, E. and Rubio, R. (2016) Psychometric Properties of the Spanish Version of the Coping Strategies Inventory (CSI) in Older People. Anales de Psicología, 32, 355-365. https://doi.org/10.6018/analesps.32.2.216141

[13] Gómez, L., Verdugo, M., Arias, B. and Navas, P. (2008) Evaluation of the Quality of Life in Older Persons and with Disability: The Fumat Scale. Psychosocial Intervention, 17, 189-199.

[14] Folstein, M., Folstein, S. and Mchugh, P. (1975) Mini-Mental State: A Practical Method for Grading the Cognitive State of Patients for the Clinicians. Journal of Psychiatric Research, 12, 189-198.

[15] Tobin, D.L., Holroyd, K.A., Reynolds, R.V. and Wigal, J.K. (1989) The Hierarchical Factor Structure of Coping Strategies Inventory. Cognitive Therapy and Research, 13, 343-361. https://doi.org/10.1007/BF01173478

[16] Chong, A. (2012) Psychosocial Aspects That Influence the Elderly's Health. Revista Cubana de Medicina General Integral, 28, 79-86.

[17] Urzúa, A., Bravo, M., Ogalde, M. and Vargas, C. (2011) Quality of Life of Older People Living in Antofagasta. Chile. Revista Medica De Chile, 139, 1006-1014. https://doi.org/10.4067/S0034-98872011000800005

[18] Vivaldi, F. and Barra, E. (2012) Psychological Well-Being, Perceived Social Support and Health Perception among Older Adults. Terapiapsicológica, 30, 23-29.

https://doi.org/10.4067/S0718-48082012000200002 